\title{
IDEOLOGIA DE GÊNERO: OS PORQUÊS E SUAS CONSEQUÊNCIAS NO CONTEXTO DO PLANO NACIONAL DE EDUCAÇÃO BRASILEIRO 2014-2024*
}

\author{
Fernanda Marina Feitosa Coelho**
}

\section{RESUMO}

Nos debates que envolveram o Plano Nacional de Educação 2014-2024, no Brasil, foram derrubadas as explicitações diretivas, dentre as quais constavam gênero e orientação sexual. Analisando esse contexto, o presente artigo defende a necessidade da educação com base em gênero e orientação sexual no Brasil, tal como já havia sido indicado no Documento Final da CONAE 2010. Além disso, o texto explana por que gênero se tornou um grande foco de atuação política de políticos religiosos e lideranças católicas e evangélicas, de forma que sua articulação política e suas falas que apontam gênero como ideologia foram capazes de produzir fobia de gênero na população brasileira. Palavras-chave: Ideologia de gênero. Fobia de gênero. Plano Nacional de Educação 2014-2024. Religião. Pânico moral.

\section{GENDER IDEOLOGY: ITS REASONS AND CONSEQUENCES IN THE CONTEXT OF THE BRAZILIAN NATIONAL EDUCATION PLAN 2014-2024}

\begin{abstract}
In the debates that involved the National Education Plan 2014-2024, in Brazil, the explanatory directives, among which were included gender and sexual orientation, were overturned. Analyzing this context, this article defends the need for education based on gender and sexual
\end{abstract}

* O presente artigo contém fragmentos da minha dissertação de Mestrado, intitulada "'Menino Já Nasce Menino, Menina Já Nasce Menina': Fobia religiosa de gênero e suas implicações no debate sobre o Plano Nacional de Educação brasileiro no período 2012-2014", defendida e aprovada em 18 de Setembro de 2017 na Universidade Metodista de São Paulo, sob orientação da Profa. Dra. Sandra Duarte de Souza.

** Doutoranda do Programa de Pós-Graduação em Ciências da Religião da Universidade Metodista de São Paulo (UMESP). Mestra em Ciências da Religião pela Universidade Metodista de São Paulo (UMESP). Bacharela em Ciências Econômicas pela Universidade Cruzeiro do Sul (UNICSUL). 
orientation in Brazil, as already indicated in the CONAE 2010 Final Document. In addition, the text explains why gender has become a major focus of political action of religious politicians and both Catholic and evangelical leaders, so that their political articulation and their lines that point to gender as an ideology were able to produce gender phobia in the Brazilian population.

Keywords: Gender ideology. Gender based phobia. National Education Plan 2014-2024. Religion. Moral panic.

\title{
IDEOLOGÍA DE GÉNERO: LOS PORQUÉ Y SUS CONSECUENCIAS EN EL CONTEXTO DEL PLAN NACIONAL DE EDUCACIÓN BRASILEÑO 2014-2024
}

\begin{abstract}
RESUMÉN
En los debates que involucraron el Plan Nacional de Educación 20142024, en Brasil, fueron derribadas las explicitaciones directivas, entre las cuales constaban género y orientación sexual. En este contexto, el presente artículo defiende la necesidad de la educación basada en el género y la orientación sexual en Brasil, tal como ya se indicó en el Documento final de la CONAE 2010. Además, el texto explora por qué género se ha convertido en un gran foco la actuación política de políticos religiosos y líderes católicos y evangélicos, de forma que su articulación política y sus palabras que apuntan género como ideología fueron capaces de producir fobia de género en la población brasileña.
\end{abstract}

Palabras-clave: Ideología de género. Fobia de género. Plan Nacional de Educación 2014-2024. Religión. Pánico moral.

\section{INTRODUÇÃO}

Muitas são as violências relacionadas a gênero no Brasil. Desde crianças, meninas e meninos são ensinados sobre suas competências enquanto tais. Às mulheres, socialmente, cabe o cuidado do lar e a dedicação familiar. Aos homens, por sua vez, destina-se a provisão da família. Quando as mulheres se inserem no mercado de trabalho, são subvalorizadas profissionalmente, mesmo que desempenhando uma mesma função ocupada por um homem. Ao chegar em casa, após o trabalho, em sua grande maioria, continuam sua jornada de trabalho pelos filhos 
e maridos. A mulher independente é recriminada por se escolher, a mãe solteira tem que se virar para dar conta da família sozinha ao mesmo tempo em que é recriminada por não poder ser tão disponível quanto os outros funcionários, mesmo que se disponha. Um homossexual que se comporta como homem tem um status diferenciado, socialmente, em comparação àquele que se comporta como mulher. As travestilidades e transgeneridades são amplamente rechaçadas pela sociedade de maneira geral, visto que ao homem é ofensivo querer se tornar como mulher e, consequentemente, descer um degrau na hierarquia dos sexos, bem como é inaceitável à mulher poder subir esse degrau. Essas são somente algumas das violências destinadas àqueles e àquelas que não abraçam seus destinos naturais e natos enquanto homens e mulheres.

A falta de entendimento sobre a realidade da diversidade de gênero e das diferentes necessidades características das diversas minorias de gênero - mulheres, mulher lésbica, homem gay, mulher transexual, homem transexual, dentre outras - gera complicações no ambiente escolar que chegam ao limite da violência, não somente verbal ou simbólica, mas também física. Tais desigualdades cotidianamente presentes na vivência escolar motivaram a inclusão da diretriz de gênero na proposição do Plano Nacional de Educação (PNE). A proposta do segundo PNE foi concebida como resultado da realização de inúmeros encontros de profissionais e organizações da área da educação, dentre os quais, as diferentes conferências municipais e estaduais que ocorreram em 2009 e a Conferência Nacional de Educação (CONAE), realizada em 2010 (Sandra Duarte de SOUZA, 2014).

Entretanto, os debates que envolveram o PNE contaram com a presença e o protagonismo de lideranças politicorreligiosas que se articularam de forma a destituir a diretriz de gênero do documento final e caracterizá-la como ideologia de gênero, a fim de invisibilizar a necessidade de se trabalhar as desigualdades de gênero e orientações sexuais de maneira específica e dar devida importância ao tema que perpassa a realidade das escolas brasileiras. Foi utilizada a metodologia bibliográfica-documental, com o intuito de analisar falas que se referem a gênero enquanto ideologia, distorcendo o conceito e sua amplitude. Nesse contexto, o presente artigo intenta demonstrar como a presença 
politicorreligiosa no Congresso Nacional e nos debates que levaram à construção do PNE 2014-2024 advoga pelas moralidades e oferece a retomada de um forte conservadorismo no Brasil, conformando empecilhos à cidadania verdadeira de brasileiras e brasileiros e retardando o processo de consolidação da laicidade brasileira.

\section{POR QUE GÊNERO? A NECESSIDADE DE SUPERAÇÃO DAS DESIGUALDADES EDUCACIONAIS COM BASE EM GÊNERO E ORIENTAÇÃO SEXUAL}

Para entender as motivações de inclusão das diretrizes de gênero e orientação sexual no Plano Nacional de Educação, precisamos nos voltar para o Documento Final da Conferência Nacional de Educação de 2010, documento norteador do PNE. Ainda, para discutir educação de gênero na perspectiva da CONAE 2010 seria necessário compreender os conceitos de educação com qualidade social e de gestão democrática, pois, se a intenção da educação democrática qualitativa é a garantia de direitos por meio de políticas públicas, então a discriminação das diversidades já existentes nas instituições educativas impede uma democracia real. Em um contexto mais amplo, cabe destacar a importância da educação na formação de cidadãs e cidadãos e, por conseguinte, no processo democrático.

O Documento Final da CONAE 2010, contextualizado no processo democrático, coloca como responsabilidade do Estado o pleno desenvolvimento das pessoas por meio de práticas concretas no espaço escolar. Neste sentido,

A educação com qualidade social e a democratização da gestão implicam a garantia do direito à educação para todos, por meio de políticas públicas, materializadas em programas e ações articuladas, com acompanhamento e avaliação da sociedade, tendo em vista a melhoria dos processos de organização e gestão dos sistemas e das instituições educativas (CONAE, 2010, p. 41, negrito/grifo no original, itálico da autora).

Seja no caso da educação básica ou superior, a gestão democrática é caracterizada pelo referido Documento como "um importante instru- 
mento do processo de superação do autoritarismo, do individualismo e das desigualdades socioeconômicas" (CONAE, 2010, p. 43).

Reconhecendo a heterogeneidade e pluralidade social e cultural dos diferentes sujeitos sociais e, consequentemente, a diversidade, a CONAE 2010 define a instituição educativa como "lugar de pessoas e de relações" (CONAE, 2010, p. 56), configurando-a, portanto, como um espaço de representações sociais. Nesse sentido, o Documento evidencia a existência de relações de violência e de não reconhecimento das diferenças como marcadores dos altos índices de abandono escolar. Dessa forma, o documento confere papel estratégico à construção de uma educação que promova essas superações contemplando as necessidades das minorias e dos grupos historicamente excluídos.

As discriminações, no Brasil e de maneira geral, perpassam todos os eixos de diversidade (em outras palavras, fatores de exclusão), direta e indiretamente, dificilmente de maneira isolada. A cultura, a partir do reflexo de sujeitos de gênero, adquire uma marca que expressa a ordem na sociedade, estas que por sua vez podem ser analisadas em sua dimensão de gênero (Marcela LAGARDE, 2008, p. 38). Essa organização cultural compulsória ocorre, muitas vezes, com consequências nas vidas de quaisquer pessoas que não se adaptem nessa moldura e que não se escondam em seus devidos armários. Nesse sentido, as violências comumente percebidas como homofobia, quando olhadas de perto, não se dirigem somente e necessariamente às pessoas LGBT (Lésbicas, Gays, Bissexuais, Travestis e Transexuais), mas a todos e todas. Segundo Richard Miskolci:

Daí ser simplista resumir essas violências no termo "homofobia", à violência dirigida a homossexuais, pois essas violências se dirigem a todos e todas, apenas em graus diferentes. Essas violências são expressão do heterossexismo, da forma como somos socializados dentro de um regime de terrorismo cultural. Uso esse termo forte "terrorismo cultural", para ressaltar que se trata de algo coletivamente imposto e experienciado; sobretudo, algo que vai além de atos isolados de violência (Richard MISKOLCl, 2013, p. 34).

Perceber a violência contida na imposição velada de comportamento é, assim, perceber gênero e as marginalizações e reações que os 
comportamentos que quebram com a fixidez dos papéis destinados aos sexos causam na sociedade. É possível, ainda, entender o porquê de as pessoas estarem em constante estado de vigilância no que diz respeito ao comportamento social. Essa justificação, para o autor, encontra-se no medo da violência. Assim,

(...) há uma lógica de imposição de normas por trás de uma forma de violência sempre à espreita, pois quando sabemos que ela pode acontecer, mas não quando nem de onde ela virá, aprendemos a nos comportar de forma "segura", ou seja, de uma forma que nos coloque ao abrigo de suas manifestações. O terrorismo cultural é um nome que busca ressaltar a maneira como opera socialmente o heterossexismo, fazendo do medo da violência a forma mais eficiente de imposição da heterossexualidade compulsória (Richard MISKOLCI, 2013, p. 34).

É para lidar com essa realidade de maneira concreta e promover uma educação marcada pela justiça social que a CONAE 2010 desmascara a profundidade das desigualdades sociais, de classe, de gênero, étnico-raciais, geracionais, e de pessoas com deficiência, quando expõe o desafio de uma educação que "reconheça e dialogue com a diversidade ampliando a noção de inclusão e igualdade social" efetivamente (CONAE, 2010, p. 123, grifo da autora nosso). Mas não só. Ao evidenciar os tipos de violências às quais alunas/os estão sujeitos/as no ambiente escolar, o Documento da CONAE 2010, consequentemente, reforça a importância do reconhecimento, por parte do Estado, dessas diferenças.

Nancy Fraser (1995, p. 69) demonstra como "a desvantagem econômica e o desrespeito cultural recorrentemente estão entrelaçados e sustentam um ao outro", ensejando "demandas pelo 'reconhecimento da diferença”" no sistema capitalista. Alinhando gênero e sexualidades, bem como os eixos de classe e raça, as forças das identidades de grupo se sobrepõem ao fator classe, politicamente, formando mobilizações em favor das bandeiras da nacionalidade, etnicidade, raça, gênero e sexualidade. Nesse sentido, "uma identidade coletiva suplanta o inte-

Economic disadvantage and cultural disrespect are currently entwined with and support one another. 
resse de classe como meio principal de mobilização política"2 (Nancy FRASER, 1995, p. 68).

Sendo os eixos de diferença inter-relacionados, Nancy Fraser propõe distinguir duas noções de injustiça, quais sejam, a injustiça socioeconômica e a injustiça cultural ou simbólica. Como exemplos de injustiça socioeconômica, a autora cita exploração laboral, marginalização econômica e privação de um padrão de vida adequado (Nancy FRASER, 1995, p. 70-71). Se a injustiça socioeconômica tem raízes na estrutura político-econômica da sociedade, a injustiça cultural ou simbólica, por sua vez, advém dos "padrões sociais de representação, interpretação e comunicação". Como formas de injustiça cultural ou simbólica, a autora especifica a dominação cultural, o ocultamento e o desrespeito.

É importante perceber que, apesar de ser possível conceituá-las isoladamente, na vida real também essas injustiças se entrelaçam e se sobrepõem, bem como, por vezes, entram em conflito. Segundo Fraser, tanto as instituições econômicas possuem uma dimensão cultural, quanto as práticas culturais contêm uma dimensão político-econômica constitutiva e irredutível; isso porque, da mesma forma que instituições econômicas são atravessadas por significados e normas, as prátcas culturais estão sujeitas aos recursos materiais (Nancy FRASER, 1995, p. 72). A autora ainda distingue as diferentes soluções para essas injustiças, de forma que:

O remédio para a injustiça econômica é algum tipo de reestruturação político-econômica. (...) O remédio para a injustiça cultural, em contraste, é algum tipo de mudança cultural ou simbólica. Isto poderia envolver a revalorização das identidades desrespeitadas e dos produtos culturais dos grupos difamados. Também poderia envolver reconhecimento e valorização positiva da diversidade cultural ${ }^{3}$ (Nancy FRASER, 1995, p. 73).

Na visão de Nancy Fraser (1995), a injustiça sofrida pelos homos-

Group identity supplants class interest as the chief medium of political mobilization.

The remedy for economic injustice is political-economic restructuring of some sort. (...) The remedy for cultural injustice, in contrast, is some sort of cultural or symbolic change. This could involve upwardly revaluing disrespected identities and the cultural products of maligned groups. It could also involve recognizing and positively valorizing cultural diversity. 
sexuais é sumariamente uma questão de reconhecimento por ser uma "sexualidade menosprezada, arraigada na estrutura cultural-valorativa da sociedade". É por isso que antes de superar a homofobia, é necessário entender os valores e práticas culturais que privilegiam a heterossexualidade. Isso ocorre toda vez que uma ação é tomada "negando respeito igual para gays e lésbicas e recusando a reconhecer a homossexualidade como um modo legítimo de sexualidade"4 (Nancy FRASER, 1995, p. 7778). Nessa perspectiva, a autora explana que:

Gays e lésbicas sofrem de heterossexismo: a construção autoritária de normas que privilegiam a heterossexualidade. Junto com isso vai a homofobia: a desvalorização cultural da homossexualidade. Com sua sexualidade depreciada, homossexuais estão sujeitos à vergonha, ao assédio, à discriminação e violência, ao mesmo tempo em que são negados direitos legais e proteções iguais - todos fundamentalmente negações do reconhecimento. Para ter certeza, gays e lésbicas sofrem graves injustiças econômicas; Eles podem ser sumariamente demitidos do trabalho e lhes são negados os benefícios sociais baseados na família5 (Nancy FRASER, 1995, p. 77).

O paradigma oculta a diversidade quando nega sua existência. Quando a heterossexualidade se torna o ponto de partida da legitimação, todas as outras sexualidades são invisibilizadas.

No caso de gênero, Fraser percebe uma ambivalência nas injustiças, em que, em uma construção binária, paradigmaticamente ocorre uma apreciação dos homens em oposição a uma depreciação das muIheres (Nancy FRASER, 1995, p. 78-79).

Porque papéis específicos são culturalmente destinados a homens e mulheres, “o resultado é uma estrutura político-econômica que

$4 \quad(.$.$) deny equal respect to gays and lesbians, and refuse to recognize homosexuality as a$ legitimate way of being sexual.

5 Gays and lesbians suffer from heterosexism: the authoritative construction of norms that privilege heterosexuality. Along with this goes homophobia: the cultural devaluation of homosexuality. Their sexuality thus disparaged, homosexuals are subject to shaming, harassment, discrimination, and violence, while being denied legal rights and equal protections - all fundamentally denials of recognition. To be sure, gays and lesbians also suffer serious economic injustices; they can be summarily dismissed from work and are denied family-based social welfare benefits. 
gera modos de exploração, marginalização e privação" ${ }^{6}$ (Nancy FRASER, 1995, p. 78). Os danos decorrentes das estruturações provocadas por gênero, entretanto, não se restringem às mulheres. Fraser alerta que:

Esta desvalorização se expressa em um espectro de danos sofridos pelas mulheres, incluindo a violência sexual, a exploração sexual e a violência doméstica difusiva; as representações estereotipadas, banalizadoras, objetificadoras e humilhantes na mídia; o assédio e a depreciação em todas as esferas da vida cotidiana; a sujeição às normas androcêntricas, nas quais as mulheres aparecem inferiores ou desviantes e que contribuem para prejudicá-las, mesmo na ausência de qualquer intenção de discriminar; a discriminação atitudinal; a exclusão ou marginalização das esferas públicas e corpos deliberativos; e a negação de direitos legais plenos e proteções igualitárias? (Nancy FRASER, 2001, p. 260-261).

A superação dessa estrutura, já conformada na sociedade, "requer decentralizar as normas androcêntricas e reavaliar um gênero desprezado. A lógica do remédio é semelhante à da sexualidade: reconhecer positivamente uma especificidade de um grupo desvalorizado ${ }^{8}$ " (Nancy FRASER, 1995, p. 79). Na busca por visibilizar as diferenças ao invés de colocá-las em uma nova posição de conflito, consequentemente estabelecendo novas hierarquias, Nancy Fraser usa a homossexualidade e a Teoria Queer para estabelecer um objetivo transformativo que valoriza a pluralidade e a heterogeneidade existentes na sociedade por meio da desconstrução, por exemplo, da dicotomia homo-hétero. Para

6 The result is a political-economic structure that generates gender-specific modes of exploitation, marginalization, and deprivation.

7 This devaluation is expressed in a range of harms suffered by women, including sexual assault, sexual exploitation, and pervasive domestic violence; trivializing, objectifying, and demeaning stereotypical depictions in the media; harassment and disparagement in all spheres of everyday life; subjection to androcentric norms in relation to which women appear lesser or deviant and which work to disadvantage them, even in the absence of any intention to discriminate; atitudinal discrimination; exclusion or marginalization in public spheres and deliberative bodies; and denial of full legal rights and equal protections.

8 It requires decentering androcentric norms and revaluing a despised gender. The logic of the remedy is akin to the logic with respect to sexuality: it is to accord positive recognition to a devalued group specificity. 
ela, “a questão não é dissolver toda a diferença sexual em uma única identidade humana universal; mas sim sustentar um campo sexual de diferenças múltiplas, não-binárias, fluídas, sempre móveis"9 (Nancy FRASER, 1995, p. 83).

Na educação, também, essa revalorização é imprescindível. A reavaliação das relações depreciadas, no cotidiano escolar pode ajudar a visibilizar a diversidade. Para Richard Miskolci (2013, p. 55), "em uma perspectiva não normalizadora, educar seria uma atividade dialógica”. Assim, não se educa para homogeneizar, mas para o aprendizado por meio das diferenças.

O próprio Documento Final da CONAE 2010 procura articular os temas de gênero e orientação sexual, de forma que estes perpassam todas as perspectivas integrantes de uma educação que enseje "justiça social, educação e trabalho, considerando a inclusão, a diversidade e a igualdade de forma concreta e radical" (CONAE, 2010, p. 129, grifos no original). Para tanto, o Documento explicita tal necessidade no tocante às relações étnico-raciais, à educação quilombola, à educação especial, à educação do campo, à educação indígena, à educação ambiental, quanto à gênero e à diversidade sexual, às crianças, aos adolescentes e aos jovens em situação de risco, à formação cidadã e profissional, à educação de jovens e adultos, à educação prisional, à educação dos/as pescadores/as, à educação em direitos humanos e à educação religiosa. Segundo Adriana Laplane e Rosângela Prieto (2010, p. 921), o conteúdo do material subsidiário leva em conta amplamente "especificidades históricas, políticas, de lutas sociais e ocupam lugares distintos na Constituição e consolidação das políticas educacionais"”.

Cabe então retomar a realidade atual e perceber o caráter heterossexista da produção de conhecimento atual. Richard Miskolci (2013, p. 47) alerta que "quando algo se apresenta como neutro, como "científico", deve-se desconfiar de que foi feito em uma perspectiva masculina, branca, ocidental, cristã e heterossexual". Essa produção de conhecimento, portanto, nunca é neutra, mas está pautada em uma cultura, notadamente, permeada por valores com fundamentação eurocêntrica,

The point is not to dissolve all sexual difference in a single, universal human identity; it is rather to sustain a sexual field of multiple, debinarized, fluid, ever-shifting differences. 
patriarcal e cristã hegemônica, em outras palavras, no que diz respeito à gênero e à sexualidade, heterocêntrica.

No caso das pessoas que não preenchem os requisitos heterocêntricos da cultura brasileira, ilegitimidade e negação de direitos plenos são conferidos a todas as práticas sexuais que divergem dos valores estabelecidos como norma. No caso das mulheres, essa desvalorização é expressa por meio do sexismo cultural, termo que Nancy Fraser (1995, p. 79) define como "a desvalorização e depreciação aguda das coisas vistas como 'femininas', paradigmaticamente" ${ }^{10}$. Para a autora:

Superar a homofobia e o sexismo requer mudança nas valorações culturais (assim como em suas expressões legais e práticas) que privilegiam a heterossexualidade, negando respeito igual para gays e lésbicas e recusam reconhecer a homossexualidade como um modo legítimo de sexualidade ${ }^{11}$ (Nancy FRASER, 1995, p. 77-78).

Ora, levando em consideração o Documento da CONAE 2010 e as discussões aqui realizadas, sabemos que a escola tem papel central na formação e transmissão de valores culturais, por ser, depois da família, um dos primeiros espaços de socialização de crianças e adolescentes em formação de suas percepções sobre cidadania e respeito à diversidade pelo contato direto com o diferente. Por que gênero? Se existe a necessidade de tratar de temas como gênero e orientação sexual em um documento que se propunha a nortear discussões de vital importância para o PNE 2014-2024, isso vem da constatação de que o ambiente escolar tem sido, na verdade, o oposto disso. Nossas instituições educacionais continuam, em variadas medidas, a reproduzir valores discriminatórios e excludentes ao invés de problematizá-los como prejudiciais ao aprofundamento da democracia e da laicidade por meio de políticas efetivas de inclusão. Assim, o insistente investimento na explicitação de discriminações com base em gênero e orientação sexual nesse Documento é o de, justamente, transformar valorações culturais negativas

10 The pervasive devaluation and disparagement of things coded as 'feminine', paradigmatically.

11 Overcoming homophobia and heterosexism requires changing the cultural valuations (as well as their legal and practical expressions) that privilege heterosexuality, deny equal respect to gays and lesbians, and refuse to recognize homosexuality as a legitimate way of being sexual. 
e prejudiciais àqueles sujeitos considerados diferentes, seja em termos de gênero, orientação sexual, raça/etnia e outros.

\section{PORQUE GÊNERO. A DEFESA ESTRATÉGICA DO CONSERVADORIS- MO NO CONGRESSO NACIONAL}

As ações dos chamados grupos minoritários em favor da formalização de seus direitos e decorrente afirmação como cidadãos ocasionam a formação de novas leis e lhes garantem algum grau de igualdade em meio à sociedade. Por sua vez, a ação de políticos religiosos ${ }^{12}$ em favor dos direitos que acreditam ser naturais ou determinados pela vontade de Deus, empurra uma parcela da sociedade, especificamente aqueles que não se enquadram nesses padrões do que é direito ou correto, para um lugar mais afastado de sua cidadania plena, desprotegendo-os de reconhecimento não só por parte do Estado, mas também por parte da própria sociedade dominante que se entende como maioria e que, sendo assim, permanece em um lugar de primazia, com direitos privilegiados (por serem reconhecidos) e, portanto, superiores, se podemos falar em uma hierarquia de cidadãos de direito.

Nesse contexto e para analisar as questões referentes à consagração da ideologia de gênero no Brasil, e suas consequências práticas na vida de cidadãos e cidadãs marginalizados/as, dentro do processo de consolidação do PNE 2014-2024, é necessário compreender como a participação de políticos evangélicos no cenário político brasileiro determinou uma nova percepção do processo de laicidade, na história recente.

Com o intuito de esclarecer possíveis confusões, cabe aqui explicitar aquilo que entendemos por laicidade, a saber, processos especificamente político-legais (Jean BAUBÉROT; Micheline MILOT, 2011). Vale ressaltar que para alcançar o objetivo de compreender as particularidades locais, a complexidade do processo de laicidade e de suas diversas formas de

\footnotetext{
12 Embora as parlamentares evangélicas não tenham se colocado contra a chamada "ideologia de gênero", seus posicionamentos neutros também se demonstraram prejudiciais às mulheres que estas deveriam representar. Nesse sentido, toda a disputa se construiu em torno da heteronormatividade e por homens brancos, heterossexuais, cristãos, tradicionalistas e de classes privilegiadas.
} 
composição nos diferentes países, é perceptível, segundo Jean Bauberót e Micheline Milot (2011), que "naturalmente, as configurações laicas são muito diferentes de um país para outro, o princípio da separação entre política e religião é muitas vezes uma questão de grau" (Jean BAUBÉROT; Micheline MILOT, 2011, p. 84).

Isso porque a laicidade tem relação estrita com a própria formação de uma democracia real na sociedade, obviamente (e redundantemente), para todos. Tal informação, embora inequívoca, carece de explicitação, pois, como veremos, os discursos de políticos religiosos constantemente aludem aos direitos de LGBTs como a imposição de uma minoria sobre a maioria. Entretanto, ressaltamos que a democracia real defende o direito de todos, independentemente de suas posições político-hierarquicamente definidas.

Nesse sentido, e reforçando a já mencionada relação entre laicidade e democracia, concordamos com Jean Baubérot e Micheline Milot, quando os autores definem a neutralidade do Estado e a separação entre este e a religião como fundamentais à coexistência laica e à garantia de igualdade, inclusive em articulação com a liberdade de consciência e de religião. Desta maneira:

Para fazer com que o conceito de laicidade seja mais operacional para analisar os regimes de gestão de diversidade religiosa, parece necessário tomar estes quatro princípios inter-relacionados que se articulam. Os dois princípios sobre os quais a tolerância gradualmente foram traduzidos em lei, a liberdade de consciência e de religião e sua extensão necessária à igualdade, então os dois princípios de gestão da política, onde a liberdade de consciência está de acordo com uma vontade de justiça igual para todos, garantido por um Estado neutro para as diferentes concepções da vida boa que coexistem na socieda$\mathrm{de}^{13}$ (Jean BAUBÉROT; Micheline MILOT, 2011, p. 80, grifos da autora).

13 Afin de rendre la notion de laïcité la plus opératoire possible pour analyser les régimes d'aménagement de la diversité religieuse, il nous paraît nécessaire de tenir compte de ces quatre principes interdépendants qui s'articulent entre eux. Le deux principes relatifs à la tolerance qui ont graduellement été traduits dans le droit, la liberte de conscience et de religion et son prolongement nécessaire dans l'égalité, puis les deux principes d'aménagement du politique où la liberte de conscience se trouve, conformément à une volonté d'égale justice pour tous, garantie par um État neutre à l'égard des diferentes conceptions de I avie bonne qui coexistente dans la société. 
Sendo esses quatro princípios inter-relacionados, cabe explicar ainda que, para os autores, a análise da laicidade alcança necessariamente o político e, consequentemente, o Estado como responsável pelo agenciamento da justiça e igualdade, e não como legitimador da exclusão, forma que, como veremos, foi instrumentalizada por parlamentares e lideranças religiosas nas tramitações do PNE 2014-2024.

A laicidade se constrói de forma dinâmica. Cabe esclarecer, entretanto, que na dinamicidade desse processo, a promulgação de direitos não implica em sua necessária permanência, visto que a criação de tensões políticas por parte dos atores religiosos, como demonstraremos posteriormente, culmina em novos Projetos de Lei ${ }^{14}$ que constroem novas formas de obstaculização desses mesmos direitos e, portanto, reforçam as discriminações com relação às chamadas minorias. Foi também o que ocorreu no processo de consolidação do PNE 2014-2024, por meio do apelo discursivo à chamada ideologia de gênero.

Arrazoar a ingerência politicorreligiosa, no Brasil, perpassa a discussão da laicidade e das tensões existentes nas relações entre religião e Estado, especificamente no campo político (Emerson GIUMBELLI, 2013; 2008). Nos grandes embates políticos que envolvem atores evangélicos e nas campanhas que estes promovem é possível perceber, de um lado, o tipo de agenda que eles expandem suas intenções políticas e, de outro, a obstrução dos direitos de todos e todas aqueles e aquelas que se opõem ao seu modo de viver e exercer suas identidades de gênero e/ou orientações sexuais.

Os evangélicos, atualmente, possuem expressiva participação e ingerência no cenário político. A agenda da bancada evangélica, formalmente constituída como Frente Parlamentar Evangélica, por sua vez, distingue-se de longa data por seu foco em questões morais (Sandra Duarte de SOUZA, 2014). A constituição de tais obstáculos se dá, especificamente, porque a FPE, enquanto formação politicamente

14 No caso da ideologia de gênero, a retirada da diretriz que promovia a erradicação das discriminações explicitadas, incluindo gênero e orientação sexual, se traduziu no grande jargão da obstaculização das agendas de gênero, notadamente direitos concernentes às chamadas minorias sexuais; sendo ainda considerado como precedente para o obstinado ataque ao termo em PLs e PDCs referentes aos Planos Municipais de Educação e à retirada dos termos de outros documentos oficiais. 
organizada, utiliza o espaço público para lograr efeito na produção legal de suas crenças. Semelhantemente, no caso do PNE 2014-2024, a FPE, com o recurso ao discurso da ideologia de gênero, fincou grande obstáculo à consolidação das agendas de gênero ocasionando alguma retomada do conservadorismo no Brasil e deslocando o papel de Estado de promotor de direitos para guardião da moralidade por eles militada. Nesse sentido, esta pesquisa busca oferecer pistas e ferramentas para o entendimento futuro das medidas com que a ideologia de gênero reestabelecerá o conservadorismo efetivamente no país.

Ademais, o ativismo politicorreligioso, da forma como é realizado por alguns membros da Frente Parlamentar Evangélica, legitima sua ocupação na esfera pública porque sua participação se dá por meio do uso de ferramentas e instrumentos politizados. Para fazer valer suas crenças, os religiosos da FPE utilizam o apelo à lei e também ao científico. É o que indica o relato de Christina Vital da Cunha e Paulo Vitor Leite Lopes sobre as entrevistas contidas em sua pesquisa com integrantes da FPE. Notadamente:

Nas entrevistas que realizamos com os integrantes da FPE, buscamos acessar a dinâmica interna a partir da qual organizam os seus trabalhos. Nos relatos, eles faziam questão de salientar o que seria o caráter mais científico da frente atualmente, buscando se afastar do estigma que pesa sobre a religião no Parlamento e também da negatividade associada socialmente à imagem dos evangélicos, sobretudo os pentecostais e neopentecostais. Essa negatividade remeteria a um universo pouco ilustrado, de precariedade, de baixa escolaridade e pobreza. Frisavam que seus argumentos não eram estritamente religiosos, que eles eram científicos, técnicos, ligados ao campo da economia e da defesa do Estado Nacional (Cristina VITAL DA CUNHA; Paulo Victor Leite LOPES, 2012, p. 156).

Os autores percebem esse comportamento difuso na atuação política de participantes da FPE. É essa atuação política concentrada em questões morais que lhes confere certo poder de decisão sobre determinadas agendas. Tal instrumentalização é configurada de apelos recorrentes a argumentos científicos e técnicos, da formalização de discursos sobre pautas (principalmente dos direitos sexuais e repro- 
dutivos) e pela judicialização de argumentos, ou seja, pelo apelo à lei. Com alegações estrategicamente elaboradas com o intuito de reforçar suas pautas.

Além do constante reforço aos ideais propostos pela ética cristã, a atuação de políticos evangélicos no Congresso Nacional é fortemente caracterizada pela articulação de discursos imbuídos de juízos de valor sobre todas as práticas e, consequentemente, todos os indivíduos que vivem uma vida dissonante de suas prédicas, a agenda moral evangélica encontra terreno fértil na sociedade que ecoa suas falas, muitas vezes sem buscar embasamento técnico para desconstruí-las. Um dos recursos mais perceptíveis nas mais diversas falas de políticos religiosos (não somente evangélicos) é o apelo ao medo. De forma semelhante a Christina Vital da Cunha e Paulo Vitor Leite Lopes, podemos observar uma bricolagem de recortes científicos acrescidos de conclusões valorativas com aparência científica nos discursos que referenciam gênero como ideologia.

Ora, sabe-se que a moralidade não resume os interesses políticos da FPE, entretanto sua defesa é a porta de manutenção da posição de poder da bancada e se constitui como sua moeda de troca para obter vitória, mesmo que em outras agendas políticas, como aquelas que envolvem interesses econômicos particulares de seus membros e até mesmo das igrejas por estes frequentadas, por meio da isenção de impostos e outras disponibilizações do serviço público, tais quais, concessões midiáticas e permissões para uso do espaço público para a realização de eventos religiosos. O que buscamos com isso afirmar é que a imprescindibilidade de sua defesa permite à bancada evangélica, na verdade, a estratégica garantia de seu espaço no poder. Nesse sentido, Cristina Vital da Cunha e Paulo Victor Leite Lopes (2012, p. 173) evidenciam que "o controle de algumas agendas pelos evangélicos no Congresso Nacional é uma importante moeda de troca no jogo político que Ihes possibilita o reconhecimento e a consolidação de sua atuação na Câmara Federal e no Senado" (Cristina VITAL DA CUNHA; Paulo Victor Leite LOPES, 2012, p. 176). Os autores, ainda, afirmam a possibilidade de desencadeamento de medos relacionados aos pânicos morais por conta da facilidade de acolhimento desses discursos. Assim, a impor- 
tância de entender o apelo ao medo por trás desses discursos se dá em decorrência do acolhimento que tais falas encontram no pensamento da sociedade brasileira.

Especificamente no processo de consolidação e sanção do PNE 2014-2024, a estratégia utilizada foi uma constante evocação da chamada ideologia de gênero e das supostas consequências maléficas que a conscientização de gênero traria para a sociedade brasileira. Tal discurso, amplamente utilizado nos debates políticos relacionados aos direitos sexuais e reprodutivos, defende a família natural, bem como, os papéis sociais adequados a mulheres e homens na sociedade. Como destaca Sandra Duarte de Souza (2008), a validação do argumento natural por meio da religião se dá por meio da sacralização das diferenças biológicas que também naturalizariam as hierarquias sociais.

É importante perceber que, para além da promoção de uma agenda moralizante que insere e reinscreve na sociedade a dualidade do pensamento dominante patriarcal, as falas e discursos articulados pela Frente Parlamentar Evangélica produzem reações na sociedade que se aproximam ao pânico de pessoas que pensam de modo diferente, por exemplo, que apoiam a descriminalização do aborto, o casamento de pessoas do mesmo sexo e tantos outros. Sendo assim, "as representações religiosas de gênero, na medida em que produzem e reproduzem lugares diferenciados de poder de acordo com o sexo biológico, possuem papel ativo na produção da desigualdade de gênero" (Sandra Duarte de SOUZA, 2008, p. 25). Esse foco de políticos evangélicos em questões sexuais e reprodutivas, além de ocasionar medos, produz (simbolicamente) preconceito, pois ensina o modo correto de viver, correspondentemente, pregando que todas as outras maneiras de se comportar e vivenciar as sexualidades são erradas.

Contudo, cabe ressaltarmos que a cosmologia religiosa dominante, no que diz respeito a gênero, orientação sexual e sexualidades, vai ao encontro do pensamento hegemônico brasileiro. O que queremos dizer com isso é que devido à proximidade desses universos de sentido, a fobia religiosa de gênero na sociedade brasileira pode ser facilmente traduzida em fobia de gênero, uma vez que a consciência coletiva nem sempre se fundamenta no discurso religioso, apesar de ser interferido 
por este, no caso do Brasil, sobretudo politicamente. No Brasil, para além da lei, tais discursos promovem pânico de gênero entre as pessoas que sentem suas fobias legitimadas pelas falas católicas e protestantes nos diferentes cenários, incluindo o político. Por isso, antes de discutirmos como a fobia religiosa de gênero é produzida pelo discurso da ideologia de gênero no contexto das tramitações do PNE, nos deteremos na análise do processo de laicidade brasileiro, para também caracterizar a aceitação e validação de gênero como ideologia como um retrocesso à sua consolidação.

\section{3 “IDEOLOGIA DE GÊNERO": A CARTADA DECISIVA}

Especificamente no que diz respeito a gênero, as más interpretações veiculadas no contexto dos debates relacionados ao Plano Nacional de Educação, como veremos a seguir, consagraram o termo conformando a ideologia de gênero termo decisivo na retirada da diretriz que aqui defendemos, corrompendo os saberes de gênero, conformando fobia na população e, consequentemente, dificultando a difusão íntegra dos estudos de gênero.

Sabe-se que a religião é um importante produtor de sentido na sociedade, estruturando e consolidando o saber dominante, bem como legitimando a realidade historicamente construída como óbvia (Clifford GEERTZ, 2008). Nesse contexto, entretanto, gênero poderia ser mais um dos saberes desenvolvidos na sociedade e não necessariamente chamar a atenção. O que nos parece peculiar é a contundência com que religiosos atacam a categoria e sua urgência em suprimi-la. A presente seção busca, assim, compreender de que maneira o discurso politicorreligioso tece gênero como ameaça à nação brasileira e seus alicerces em seus discursos, produzindo pânico moral de gênero.

Ora, se o pânico moral pode ser entendido como a ameaça aos valores e interesses sociais, fobia religiosa de gênero, da forma como compreendida aqui, diz respeito à produção sociorreligiosa de pânico moral originada do discurso construído que provoca fobia de gênero e, à vista disso, de tudo aquilo que nesses discursos é relacionado a ela. Não obstante, tais argumentos são difundidos com a intenção de perpetuar as crenças morais e moralizantes dos diferentes setores re- 
ligiosos que participam ativamente da política brasileira e de promover sua manutenção no poder.

Para compreender como o processo que transformou a categoria gênero em ideologia foi bem-sucedido, a ponto de produzir pânicos morais que reverberaram na sociedade brasileira, é necessário dar devido destaque aos seus formuladores, pois estes foram, fundamentalmente, lideranças e políticos religiosos com forte poder de influência na mídia brasileira, a saber, o deputado Pastor Marco Feliciano (PSC-SP), o deputado Pastor Eurico (PSB-PE), Eros Biondini (PROS-MG) e o padre Paulo Ricardo. Ao analisar a religião como sistema estruturador, Pierre Bourdieu (2011) explana sua capacidade de associar os mundos natural e social à sua forma de leitura do conjunto de normas (ethos religioso) de modo a garantir a consagração/legitimação das coisas que definem o seu conjunto. De acordo com Pierre Bourdieu (2011):

Por todas essas razões, a religião está predisposta a assumir uma função ideológica, função prática e política de absolutização do relativo e de legitimação do arbitrário, que só poderá cumprir na medida em que possa suprir uma função lógica e gnosiológica consistente em reforçar a força material ou simbólica possível de ser mobilizada por um grupo ou uma classe, assegurando a legitimação de tudo o que define socialmente este grupo ou esta classe (Pierre BOURDIEU, 2011, p. 45-46, grifos no original).

Se considerarmos que os discursos que reduziram a categoria gênero à ideologia se construíram, justamente, como forma de legitimar o arbitrário, ou seja, para absolutizar as configurações sexistas, fruto do patriarcalismo, e subjugar mulheres e pessoas LGBT à violência diária, não poderíamos considerar esses mesmos discursos ideológicos? Pierre Bourdieu (2011) acrescenta que, na defesa de um conjunto de características que definam um grupo religioso, o efeito de consagração se dá na transformação de propriedades relativas e arbitrárias em naturalização e eternização. Nesse sentido, constrói-se por meio do discurso e da legitimação das características de um conjunto de coisas que sempre foram assim.

No contexto das discussões que envolveram o PNE 2014-2024, a família tradicional é o grande símbolo de identidade nacional e cristã, 
comumente evocado nas falas religiosas. Cabe, portanto, ressaltar que a família que os evangélicos defendem como tradicionalmente brasileira e, para eles, digna de proteção, tem uma configuração específica, que também faz parte do conjunto de elementos e estilos de vida que são consagrados, sacralizados e naturalizados pelos princípios cristãos, qual seja, o pai de família dominando sobre mãe e filhos/as.

Ora, se a religião cristã detém autoridade sobre a sacralidade de determinada configuração familiar, defender a família tradicional brasileira, seria, na verdade, a defesa do poderio sobre o conservadorismo cristão. Em outras palavras, a mobilização da identidade nacional se dá em torno da força material e simbólica que a religião cristã tem no país.

Toda vez que o nomos social (Peter BERGER, 1985) é questionado por comportamentos transgressores da ordem social, ocorre uma desestabilização da ordem objetivada. Nesse contexto, uma ameaça à família nuclear seria facilmente acolhida pelo pensamento dominante da sociedade, visto que outras configurações familiares não são consideradas tradicionais. Além disso, o binarismo homem/mulher é constantemente afirmado como natural nas falas religiosas e, para o senso comum, são demarcadores identitários. Mesmo havendo outras formas de representação de gênero e de vivenciamento das sexualidades, estas são leituras feitas a partir da realidade objetivada. No tocante à sexualidade, Peter Berger (1985) utiliza o pânico homossexual como exemplo, quando afirma que:

O chamado "pânico homossexual" pode servir de excelente ilustração do terror desencadeado pela recusa desse programa. Com isso não se nega que esse terror seja também alimentado pelas apreensões práticas e remorsos de consciência, mas a sua mola propulsora fundamental é o pavor de ser alijado às trevas exteriores que separam o indivíduo da ordem "normal" dos homens (Peter BERGER, 1985, p. 37).

Não temos aqui a pretensão de separar as questões de gênero das questões de orientação sexual, mesmo porque afirmamos nesta pesquisa que os preconceitos relacionados às homossexualidades também dizem respeito a gênero. Marcelo Natividade e Leandro de Oliveira (2013, p. 26) defendem a necessidade de "(...) desvelar lógicas sociais e culturais que 
dão margem a situações de exclusão, reproduzem estigmas e inventam novos estereótipos em torno das diferenças sexuais". Não obstante, acreditamos ser necessário esclarecer como o recurso aos medos e fobias relacionados a estas populações (pela própria falta de educação para a diversidade que tiveram) podem ser utilizados no sentido de construir saber e fazê-lo parecer científico. É claro que a homossexualidade, assim como todas as formas de vivência não heterossexual e de representações não tradicionais de gênero despertam receio na maioria da população de senso comum, uma vez que sua aceitação tem consequências, quais sejam, a marginalização dos que por estas optam da sociedade de bem e sua resultante perda de status.

É nesse contexto de ocultamento das desigualdades presentes na realidade brasileira e do mascaramento dos marcadores que motivam tais violências que retomar o conceito de pânicos morais (Stanley COHEN, 2002) nos ajudará a melhor compreender as reações da população à suposta ideologia de gênero. De acordo com o já mencionado, o pânico moral se conforma a partir de uma dinâmica de estereotipação de um fenômeno social. É importante ressaltar, entretanto, que para um discurso ser plenamente acolhido pela sociedade, não basta que ele se conforme aos códigos de sentido desta. Antes, porém, o discurso legitimado precisa ser proferido por indivíduos socialmente autorizados. No que diz respeito à moralidade, pessoas acreditadas são notadamente religiosas e, no âmbito da política, aqueles que são autodeclarados religiosos, como os da Frente Parlamentar Evangélica e outras lideranças religiosas militantes da moralidade junto ao Congresso Nacional e à população.

De acordo com Angela McRobbie \& Sarah Thornton (1995, p. 560), os pânicos morais são “(...) usados por políticos para orquestrar consentimento, pelos negócios para promover vendas em certos mercados de nicho e pela mídia para tornar as questões domésticas e sociais dignas de serem noticiadas, os pânicos morais são construídos diariamente ${ }^{15 "}$. Por meio de grupos de pressão, informações e análises são construídas para contrariar a representatividade de determinado grupo (desviante).

15 (...) used by politicians to orchestrate consent, by business to promote sales in certain niche markets, and by media to make home and social affairs newsworthy, moral panics are constructed on a daily basis 
Consequentemente, os pânicos morais acessam ansiedades, relacionando comportamentos desviantes como ameaças à identidade nacional, o que levaria ao crime. Os autores afirmam que é uma estratégia usada para incitar de forma objetiva, por meio da mídia. É o que ocorreu no caso do PNE, quando a ameaça da ideologia de gênero à família tradicional brasileira e às pessoas de bem foi construída com o objetivo de deslegitimar e desqualificar a categoria gênero como uma forma útil de dirimir discriminações e opressões que as chamadas minorias sexuais sofrem desde sua formação escolar.

Essa forma de atuação que busca produzir pânico moral pode também ser entendida nos termos de Howard Becker (2008), quando o autor analisa a criação e imposição de regras estabelecidas por empreendedores morais. Segundo Becker, um dos tipos de empreendedores morais são os reformadores cruzados, pois eles "acreditam tipicamente que sua missão é sagrada” (Howard BECKER, 2008, p. 153). Assim, tudo que não corresponde à própria moralidade desses empreendedores torna-se alvo da tentativa de imposição de regras que criam os indivíduos outsiders, ou seja, os desviantes.

As análises de Howard Becker (2008) nos dão recursos para o entendimento de como atuam os parlamentares evangélicos, quando instrumentalizam o Estado para guardar a moralidade, nos termos dispostos pelo conservadorismo cristão, subtraindo a democracia aos seus próprios interesses de forma oportuna. Como exemplo concreto disso, além do caso do PNE, outra investida dessa bancada ocorreu no ano de 2010, quando foi anunciada a produção de cartilhas do Programa Escola Sem Homofobia, iniciativa do Ministério da Educação em parceria com ONGs defensoras dos direitos da população LGBT. Na ocasião, o material foi pejorativamente apelidado de kit gay. No referido episódio, os argumentos acionados também invocavam os preceitos da liberdade religiosa, apelando para o fato de que a distribuição do material passaria por cima dos pais na educação moral de seus filhos. Após pressão da bancada evangélica, a então presidente Dilma Rousseff suspendeu a distribuição do material nas escolas públicas.

Em meio às análises que envolveram as discussões sobre a cartilha e os desdobramentos que levaram a suspensão de sua distribuição, 
Christina Vital e Paulo Lopes ressaltam a participação de vários setores da sociedade (e não somente do religioso) que acionam o pânico moral da população com o objetivo de vencer os conflitos que envolvem políticas sexuais, com destaque para a "apropriação e usos de espaços políticos por segmentos conservadores e, no caso da nossa análise, em especial das bancadas religiosas" (Cristina VITAL DA CUNHA; Paulo Victor Leite LOPES, 2013, p. 149). Os autores discorrem sobre o engendramento político da FPE e a respeito da sua busca pela reprodução dos mesmos ideais que defendem e protegem na esfera política. Especificamente acerca da atuação da bancada evangélica no tocante aos direitos das mulheres e de LGBTs no Brasil. Gostaríamos de reforçar, como já mencionamos, a capacidade de capilarização dos discursos politicorreligiosos, tanto evangélicos quanto católicos, pelo uso de códigos presentes nas crenças culturais da sociedade dominante brasileira por meio do acionamento de pânicos morais que incluem ameaças à espécie humana e à família (Cristina VITAL DA CUNHA; Paulo Victor Leite LOPES, 2013).

É o que também foi reproduzido no processo de consolidação e sanção do PNE por meio da evocação constante da chamada ideologia de gênero e das supostas consequências maléficas que a conscientização da realidade de gênero e orientação sexual traria para a sociedade brasileira. A construção de gênero como ideologia, como já mencionado, é pautada em distorções conceituais e no apelo à falta de conhecimento sobre gênero para acessar medos que atingem os códigos de sentido da sociedade.

A hipótese com que desejamos encerrar a nossa discussão é a de que essa formação politicorreligiosa de pânico moral relacionado a gênero culmina na produção de fobia de gênero. Gostaríamos aqui de ressaltar que, enquanto produtora de sentidos da ordem natural na sociedade brasileira, lideranças politicorreligiosas também legitimam assimetrias na sociedade, sobretudo aquelas relacionadas a gênero. Para tanto, nos utilizaremos das falas de políticos da bancada evangélica, proferidas na reunião da Comissão Especial do PNE de 8 de abril de 2014. A previsão de encerramento das votações estava designada para o dia seguinte, mas a polêmica em torno das diretrizes de gênero e orientação sexual acabou por se tornar um novo destaque a ser debatido. 
Na referida data, grupos e parlamentares religiosos presentes na reunião sustentaram incisivamente seus posicionamentos contrários à questão de gênero e a orientação sexual no PNE. Entre estes, um dos principais opositores da ideologia de gênero, ambos como liderança religiosa e como político, foi o deputado Pastor Marco Feliciano (PSC-SP), que já possui conhecido histórico na luta contra a ampliação dos direitos das chamadas minorias sexuais durante o seu mandato como presidente da Comissão de Direitos Humanos e Minorias (CDHM) da Câmara dos Deputados no ano de 2013. O parlamentar evangélico inicia sua fala defendendo que gênero é uma questão privada, de foro íntimo e não pública ou social/educacional, desqualificando a necessidade de debates e atenção para a formação de leis que visem minimizar intolerâncias relatas. De acordo com Feliciano (PSC-SP):

A ideologia de gênero é uma construção social da imagem sobre o ser humano, ou seja, o ser humano nasce um ser amorfo. Ele vai se descobrir homem ou mulher depois, quando tiver certa idade. Se isso é de foro íntimo, por que os educadores têm que se intrometer nessa história? Por que isso tem que se tornar uma lei? (BRASIL, 2014a, s/n).

Na fala do deputado, encontramos os mesmos elementos que são utilizados, muitas vezes, para privatizar a violência contra as mulheres no Brasil. Expressões populares como em briga de marido e mulher não se mete a colher foram reproduzidas em nosso país como senso comum porque, durante muito tempo, a violência doméstica foi tratada como algo a ser resolvido dentro de casa, de maneira que esforços estatais seriam dispensáveis. Entretanto, em momento algum é dito que a violência contra a mulher também faz parte das violências com base em gênero. Além disso, a fala do parlamentar gira em torno, somente, do temor que crianças e adolescentes não se conformem aos papéis sociais atribuídos aos sexos dos sujeitos desde o seu nascimento, conferindo caráter pejorativo às identidades de gênero que não correspondem a essa norma.

Ao se concentrar apenas na ideia de que a identidade de gênero é formada ao longo da vida, o deputado Pastor ignora as violências fatídicas das discriminações baseadas em gênero e em orientação sexual, 
quais sejam, todas aquelas contra pessoas que apresentam representações de gênero que diferem da norma heterossexual cisgênera. Assim, ignorando o contexto de promoção da igualdade, Marco Feliciano (PSC-SP) enviesa a intenção da diretriz em promover, por meio de gênero e orientação sexual, as configurações não heterossexuais e não cisgêneras como algo bom, natural e tão legítimo quanto a heterossexualidade. Ora, se o deputado se opõe a essa equiparação, necessariamente admite a existência de uma hierarquia de gênero, na qual os privilégios da heterossexualidade sobrepõem todos os patamares inferiores. Ainda, além de admitir tal realidade, o deputado nega sua própria fala ao se posicionar como defensor da igualdade e da não discriminação. Retomando a discussão do kit anti-homofobia como respaldo para a sua fala, o deputado diz:

Uma coisa é não promover o preconceito, e quanto a isso eu também sou a favor. Não à discriminação! Mas o texto fala em promoção, e promoção é o quê? É dizer que é normal ou é dizer que é bom? Isso é muito problemático, porque uma coisa é dizer à criança que é normal a pessoa ser isso ou ser aquilo, outra coisa é doutriná-la dizendo que isso é bom. Podemos criar no futuro uma fábrica de pessoas amorfas. Eu me lembro de que, em 2011, quando assumi aqui este mandato, houve um problema gravíssimo dentro da Câmara dos Deputados acerca de um kit anti-homofobia que havia sido aprovado pelo MEC. Eu me lembro de que, quando isso veio à tona, os Deputados se levantaram e houve manifestações de toda a sociedade contrárias àquilo, contrárias ao vídeo, contrárias aos ensinamentos. A sociedade em peso se manifestou (BRASIL, 2014, s/n).

Como já mencionamos, a luta contra o kit anti-homofobia se deu por conta de seus oponentes o acusarem de promover o homossexualismo nas escolas brasileiras. No caso do PNE, os argumentos do parlamentar não se diferem muito, visto que considera que a ideologia de gênero buscaria doutrinar crianças de forma a produzir uma fábrica de pessoas amorfas. Assim, tais argumentos suscitam sempre os pânicos morais que envolvem, entre outras coisas, a perda da posição da heterossexualidade cisgênera como única expressão entendida como boa, ocultando que esta é também fruto de uma doutrina que expressa a já 
mencionada relação de decorrência entre sexo, gênero, práticas sexuais e desejo, ensinada e reproduzida desde o nascimento dos sujeitos (Judith BUTLER, 2015) por meio dos mais diversos mecanismos que reforçam sua obviedade.

Prosseguindo a sua argumentação, Marco Feliciano (PSC-SP) posiciona-se politicamente junto ao seu partido, invocando o argumento de que o Brasil é um país majoritariamente cristão em detrimento dos princípios da laicidade. Assim, a invocação da maioria subsidia sua luta contra a ideologia de gênero, associando-a à doutrina marxista e àquilo que chama de marxismo de gênero:

Eu só quero, então, deixar a posição deste Parlamentar, posição do meu partido, o PSC. Nós queremos votar o PNE, só não concordamos com esse destaque acerca da ideologia de gênero, lembrando mais uma vez que nosso País é um país laico, todavia de maioria cristã. E, sobre o marxismo, que foi citado aqui, talvez o pensamento do nobre Deputado tenha sido sobre o marxismo proletário, mas, quando ele cita, ele não cita o marxismo proletário, ele cita o marxismo de gênero, e é esse marxismo de gênero, marxismo que vai além do classismo, que emprega, neste momento, a desconstrução da família e a desconstrução do pensamento da sociedade (BRASIL, 2014, s/n).

Ao invocar a maioria cristã brasileira, Feliciano (PSC-SP) reconhece sua capacidade de acessar os códigos de sentido dominantes da sociedade no que diz respeito à moral sexual. Apelando para a identidade religiosa de seus eleitores e eleitoras, o deputado associa gênero à desconstrução da família e do pensamento da sociedade. Destarte, gênero visa, precisamente, a desconstrução das hierarquias e opressões decorrentes do sistema patriarcal e todas as dinâmicas que propiciam opressões dentro das instituições familiares e do pensamento da sociedade.

Ademais, existe um elemento fundamental que a invocação da maioria cristã revela quando analisamos em que esse argumento se fundamenta. Admitir proteger a opinião de uma maioria em prejuízo de qualquer minoria é, por conseguinte, advogar por assimetrias não só de gênero e orientação sexual, mas também entre grupos religiosos majoritários e minoritários, em clara oposição aos princípios democráticos e à superação das desigualdades. 
Uma vez que a fala do deputado Marco Feliciano (PSC-SP) não foi suficiente para conformar gênero como uma grande ameaça no debate que ali se propunha, o já mencionado deputado Pastor Eurico (PSB-PE) formula seu discurso com o caráter atemorizante de um suposto fim das identidades. Assim, reafirmando a crença da bancada evangélica, o parlamentar elenca consequências da aprovação do PNE com as diretrizes de gênero:

(...) quais as consequências disso? A resposta está aí: as consequências são as piores possíveis, conferindo status jurídico à chamada identidade de gênero. Não há mais sentido falar em homem e mulher, falar-se-ia apenas de gênero, ou seja, a identidade que cada um criaria para si. Esse é um ponto para o qual chamamos a atenção. Já fizemos discurso sobre isso no plenário da Casa, mostrando o absurdo que está por trás dessa terminologia (BRASIL, 2014, s/n).

Novamente, o absurdo da ideologia de gênero seria a supressão da questão de macho e fêmea, notadamente a concepção biologizante e naturalizante que associa sexo biológico à identidade de gênero, em detrimento das pessoas, de suas particularidades e de seus marcadores sociais. O parlamentar segue a sua argumentação, persistindo na família como aquela posta na Constituição, especificamente (e somente), formada por homem e mulher. Segundo ele:

V.Exa. coloca como eu antes colocava: sempre usei essa expressão gênero como identificação de homem e mulher. Mas partindo desse princípio, que agora é oriundo de outras partes do planeta, automaticamente é uma desconstrução daquilo que nós sempre defendemos, que é exatamente a questão homem e mulher e principalmente a questão família no contexto de macho e de fêmea (BRASIL, 2014, s/n).

Ao defender a família exclusivamente como aquela que se amolda na configuração tradicional ou, em suas palavras, do "contexto macho e fêmea", Eurico (PSB-PE) apela para a noção de que todas as outras configurações familiares seriam elementos que poluem a sociedade brasileira.

Ora, se nas discussões que ocorreram no Congresso Nacional, os parlamentares evangélicos representaram um grupo de pressão impor- 
tante nas tramitações do PNE, configurando gênero como comportamentos desviantes à norma heterossexual e cisgênera, os parlamentares católicos também compuseram esse grupo e, similarmente, se articularam, clamando, inclusive, pelo envolvimento de cidadãos e cidadãs das mais diversas religiões, colocando a ideologia de gênero como um inimigo comum das famílias brasileiras. Um dos principais parlamentares católicos envolvidos nesse debate foi Eros Biondini (PROS-MG), importante representante do movimento da renovação carismática católica. Segue a argumentação de Biondini (PROS-MG):

Está muito claro que todos nós somos contra qualquer tipo de preconceito, discriminação, racismo ou perseguição. Não se trata disso. O que acontece é que a inclusão da ideologia de gênero no Plano Nacional de Educação confunde extremamente aquilo que já é uma construção, uma concepção do conceito de família. Isso vem afetar diretamente aquilo que já tem sido construído nos lares das famílias católicas, espíritas, evangélicas, das famílias no Brasil. Nós queremos, sim, que toda discriminação, todo bullying, toda marginalização seja combatida. Porém, esse não é definitivamente o caminho. E se nós somos hoje aqui, Sr. Presidente, legitimados pela vontade daqueles que nós representamos, a grande maioria do povo brasileiro, é só nós vermos a quantidade imensa de manifestações por e-mails, por cartas, por mensagens que chegam de todo Brasil (BRASIL, 2014, s/n).

Nesse contexto, o deputado menciona inúmeros programas de combate ao preconceito e à discriminação, dos quais participa, como forma de dar credibilidade à sua argumentação contra gênero. Isso porque seriam instituições e pastorais desenvolvedoras de um trabalho louvável e, portanto, merecedoras de apoio e voz para decidir sobre questões relativas à violência e ao PNE. Não só houve a consulta dessas instituições, como também o parlamentar menciona a vontade de seu eleitorado, expressa por meio de formas diversas de comunicação.

Apesar de não mencionado pelo deputado, tais comunicações se dão em resposta às chamadas das próprias lideranças religiosas. Um exemplo dessa mobilização está na articulação pública dessas lideranças contra a ideologia de gênero. Dessa maneira, o envolvimento religioso no combate à categoria extrapolou as fronteiras do Congresso Nacional 
e adentrou o espaço midiático pela atuação de diversas lideranças proeminentes, como o já mencionado padre Paulo Ricardo. A seguir, uma importante convocação foi feita pelo líder católico, no período em que a Casa revisora discutia o substitutivo elaborado com a Câmara. Em 10 de março de 2014, padre Paulo Ricardo publicou em seu site:

Prezado Amigo, Está em fase final de tramitação na Câmara Federal o PL 8035/2010, de origem do executivo, que cria o PNE - Plano Nacional de Educação para os próximos 10 anos. O pedido é simples. É absolutamente necessário que você ligue para a lista de onze parlamentares abaixo e solicite que na votação do $\mathrm{PL}$, no próximo dia 19 de março, seja mantida no artigo $2^{\circ}$ do projeto, a redação aprovada no Senado. Por favor, escreva este pedido numa única mensagem, c/c oculta, para todos os deputados integrantes da lista e também para as lideranças dos partidos, cujos e-mails encontram-se no final deste texto. A família brasileira agradece (CHRISTO NIHIL PRAEPONERE, 2014, s/n).

A convocação foi realizada em outras etapas do Plano Nacional de Educação, como em seu período de tramitação pelo Senado, quando o senador Vital do Rêgo aprovou o substitutivo destituído das explicitações das diretrizes a serem superadas. A carta foi replicada por inúmeras mídias eletrônicas. Apesar de outras importantes lideranças religiosas evangélicas e católicas terem se envolvido publicamente nos debates sobre a ideologia de gênero, destacamos a importância da atuação do padre Paulo Ricardo no que diz respeito à mobilização popular junto aos parlamentares por ele apontados em sua publicação.

A família tradicional, agora família brasileira, esconde todas as outras famílias não autorizadas pelo cristianismo dominante. Ao conclamarem a família brasileira, sempre entendida em sua configuração biologizante, em outras palavras, de macho e fêmea tida como a única possibilidade correta e legítima, o discurso religioso desqualifica outras orientações sexuais e identidades de gênero e aciona pânicos morais na população brasileira, reforçando os códigos de sentido desta em oposição às ameaças à identidade brasileira e, por conseguinte, à ordem e ao bem comum. 
Seja nas falas dos parlamentares católicos, evangélicos, ou de lideranças religiosas aqui apresentadas, os debates que envolveram as tramitações do Plano Nacional de Educação possibilitaram perceber que a fobia religiosa de gênero se dá no contexto em que gênero é colocado mais que como uma ameaça, mas como um perigo a ser combatido. Nesse sentido, incentiva-se a população a lutar pela conservação do status quo e da dominação dos códigos de sentido patriarcais mascarados pelas leis da natureza. A luta pela retirada das diretrizes de gênero e orientação sexual do PNE não foi uma busca pela desideologização da educação no Brasil. Se os participantes do debate contra a categoria a acusam de ideologia, o fazem em favor da perspectiva ideológica cristã hegemônica.

\section{CONSIDERAÇÕES FINAIS}

Se o respeito à pluralidade é essencial para o aprofundamento da democracia brasileira, a atuação dos parlamentares que compõem a FPE e de seus apoiadores tem se configurado na contramão desse ideal. Como vimos ao longo desta pesquisa, em diversos momentos os parlamentares evangélicos colocaram-se contrários à ampliação dos direitos das chamadas minorias sexuais, utilizando os recursos discursivos que deslegitimam a luta da população LGBT e das mulheres. No caso do PNE, vimos como as falas que invocam uma ideologia de gênero, com o intuito de deslegitimar a categoria gênero, se tecem de forma a apelar para pânicos morais (Stanley COHEN, 2002) que envolvem, entre outros elementos, a homossexualização de crianças. Mas não é apenas esse elemento que se deve destacar de tal atuação.

$\mathrm{Na}$ construção do discurso da ideologia de gênero, a fala politicorreligiosa se utiliza, sobretudo, de uma percepção generalizada da heterossexualidade como natural, apelando para os códigos de sentido dominantes da sociedade e concatenando aprovação e reforço das massas de fiéis que os apoiam, legitimando suas participações conservadoras no governo, direta e indiretamente, e perpetuando assimetrias no que diz respeito à distribuição democrática e igualitária de direitos (Sandra Duarte de SOUZA, 2014; Fernanda Marina Feitosa COELHO, Naira Pinheiro dos SANTOS, 2016). A formação de saber que se articulou em torno da 
ideologia de gênero obscurece a reflexão aprofundada acerca de gênero e a busca por conhecimento específico desse tema ao mesmo tempo em que constrói sexualidades e papéis de gênero nocivos, reproduzindo o próprio discurso da ideologia de gênero como saber constituído. A condenação da educação de gênero, consequentemente, culminou na retirada da diretriz que explicitava a promoção da erradicação das discriminações com base em gênero e orientação sexual, entre outras. A ação de políticos religiosos, nesse contexto, hierarquiza cidadãos e cidadãs, relegando a todo aquele e aquela que não vive com o que é colocado como natural a ausência do reconhecimento e proteção do Estado e, portanto, privando-os de direitos plenos e contrariando os princípios de uma democracia real e da laicidade. Nesse sentido, o retrocesso das discussões que envolveram o PNE 2014-2024 constitui novas formas de obstaculização desses mesmos direitos e, portanto, prolonga a discriminação das chamadas minorias, inclusive com o apoio da população dominante, que pela proximidade de sentido, não se percebe (em diferentes fatores e níveis de exclusão, interseccionalmente) participante das hierarquias e da realidade de gênero.

\section{REFERÊNCIAS}

BAUBÉROT, Jean; MILOT, Micheline. Laïcité sans frontières. Paris: Seuil, 2011.

BECKER, Howard S. Outsiders: estudos de sociologia do desvio. Rio de Janeiro: Jorge Zahar, 2008.

BERGER, Peter Ludwing. O dossel sagrado: elementos para uma teoria sociológica da religião. São Paulo: Paulus, 1985.

BOURDIEU, Pierre. A economia das trocas simbólicas. São Paulo: Perspectiva, 2011.

BRASIL. Câmara dos Deputados, Comissão Especial - PL 8035/10 - Plano Nacional de Educação - Reunião No: 0300/14, de 08 de abril, 2014a. Disponível em: <http://www. camara.leg.br/internet/sitaqweb/textoHTML.asp?etapa=11\&nuSessao=0300/14\&nuQuar to $=0 \&$ nuOrador $=0 \&$ nulnsercao $=0 \& d$ tHorarioQuarto $=11: 00 \&$ sgFaseSessao $=\& D$ Data $=8 / 4 / 2$ 014\&txApelido=PL\%208035/10\%20-\%20PLANO\%20NACIONAL\%20DE\%20EDUCA\%C3\%87\%C3 \%83O\&txFaseSessao=Reuni\%C3\%A30\%20Deliberativa\%20Ordin\%C3\%A1ria\&txTipoSessao= \&dtHoraQuarto=11:00\&txEtapa $=>$

BRASIL. Câmara dos Deputados. Lei n. 13.005, de 25 de junho de 2014b. Aprova o Plano Nacional de Educação (PNE) e dá outras providências. Centro de Documentação e Informação Coordenação Edições Câmara, Brasília, DF. Disponível em: <http://www2.camara. 
leg.br/legin/fed/lei/2014/lei-13005-25-junho-2014-778970-publicacaooriginal-144468-pl. html > Acesso em 20 jun. 2016.

BUTLER, Judith. Problemas de gênero: feminismo e subversão da identidade. Rio de Janeiro: Civilização Brasileira, 2015.

CHRISTO NIHIL PRAEPONERE. Urgente: Congresso pode aprovar a ideologia de gênero como meta da educação. Disponível em: < https://padrepauloricardo.org/blog/urgente-congresso-pode-aprovar-a-ideologia-de-genero-como-meta-da-educacao > Acesso em: 10 mai. 2017.

COELHO, Fernanda Marina Feitosa; SANTOS, Naira Pinheiro dos. A mobilização católica contra a "ideologia de gênero" nas tramitações do Plano Nacional de Educação brasileiro. Religare, vol. 13, n. 1, 2016, p. 27-48

COHEN, Stanley. Folk devils and moral panics: The creation of the mods and rockers. London: Routledge, 2002, 327p.

CONAE 2010 - Conferência Nacional de Educação, 2010, Brasília. Construindo o Sistema Nacional Articulado de Educação: O Plano Nacional de Educação, diretrizes e estratégias de ação: documento referência. Disponível em <http://CONAE.mec.gov.br/images/stories/ pdf/pdf/documetos/documento_final_sl.pdf >. Acesso em 20 jun. 2016.

FRASER, Nancy. Da redistribuição ao reconhecimento? Dilemas da justiça na era pós-socialista. In: SOUZA, Jessé (Org.). Democracia hoje: novos desafios para a teoria democrática contemporânea. Brasília: Editora Universidade de Brasília, 2001, p. 245-282.

FRASER, Nancy. From Redistribution to Recognition? Dilemmas of Justice in a 'Post-Socialist’ Age. New Left Review, I, 212, 1995, p. 68-93. Disponível em: <https://pdfs. semanticscholar.org/9867/540d71b6d63ee80bea57d5b83aac7103af9o.pdf > Acesso em 20 mai. 2016.

GEERTZ, Clifford. A interpretação das culturas. Rio de Janeiro: LTC, 2007.

GIUMBELLI, Emerson. A presença do religioso no espaço público: modalidades no Brasil. Religião e sociedade, Rio de Janeiro, v. 28, n. 2, 2008, p. 80-101.

GIUMBELLI, Emerson. Para estudar a laicidade, procure o religioso. In: BÉLIVEAU, V. G. y GIUMBELLI, E. Religión, cultura y política en las sociedades del siglo XXI. Buenos Aires: ACSRM/Biblos, 2013, p. 43-68.

LAGARDE, Marcela. La multidimensionalidad de La categoría género y del feminismo. In: Género: selección de lecturas. La Habana: Caminos, 2008, p. 35-44.

LAPLANE, Adriana Lia Friszman; PRIETO, Rosângela Gavioli. Inclusão, diversidade e igualdade na CONAE 2010: perspectivas para o novo Plano Nacional de Educação. In: Educação \& Sociedade, v. 31, n. 112, p. 919-938, 2010.

MCROBBIE, Angela. \& THORNTON, Sarah. Rethinking 'Moral Panic' for multi-mediated social worlds. In: British Journal of Sociology. Vol. 46, No. 4 (Dec., 1995), p. 559-574. 
MISKOLCI, Richard. Teoria queer: um aprendizado pela diferença. Belo Horizonte: Autêntica, 2013.

NATIVIDADE, Marcelo; OLIVEIRA, Leandro de. As novas guerras sexuais: diferença, poder religioso e identidade LGBT no Brasil. Rio de Janeiro: Garamond, 2013.

SOUZA, Sandra Duarte de. “Não à ideologia de gênero!” A produção religiosa da violência de gênero na política brasileira. In: Estudos de Religião, v. 28, n. 2, jul./dez. 2014, ISSN Impresso: 0103-801X - Eletrônico: 2176-1078.

SOUZA, 2008. A relação entre religião e gênero como um desafio para a sociologia da religião. In: Caminhos, Goiânia, v. 6, n. 1, p. 13-32, jan./jun. 2008.

VITAL, Christina; LOPES, Paulo Victor Leite. Religião e Política: uma análise da atuação de parlamentares evangélicos sobre direitos das mulheres e de LGBTs no Brasil. Rio de Janeiro: Fundação Heinrich Böll, 2012.

Submetido em: 19-10-2017

Aceito em: 30-11-2017 